\title{
Superior vena cava syndrome complicating calcific uremic arteriolopathy in an ESRD male patient on maintenance hemodialysis following failed kidney transplantation
}

\author{
Macaulay Amechi Chukwukadibia Onuigbo ${ }^{1,2,3,4^{*}}$, Nneoma Agbasi $^{5}$, Abdul Khan ${ }^{2}$, Vinay Nijhawan $^{6}$, Zhibin Jiang $^{5}$
}

\begin{abstract}
We described the unusual presentation of right unilateral facial swelling in a 48-year old end-stage renal disease (ESRD) male patient on maintenance hemodialysis following a failed kidney transplant. This was subsequently confirmed to be secondary to the extrinsic compression of the superior vena cava (SVC) by a large lobulated amorphous extra-osseous right axillary mass lesion that extended into the upper right thoracic outlet. Superior vena cava venogram and balloon angioplasty led to symptomatic relief. The factors involved in the pathogenesis of calciphylaxis are discussed and the available therapeutic options for this rare albeit debilitating disease are reviewed.

Keywords: Calciphylaxis, Uremic arteriolopathy, Hemodialysis, Chronic kidney disease, Calcimimetics, End-stage renal disease Please cite this paper as: Onuigbo MAC, Khan A, Nijhawan V, Jiang Z. Superior vena cava syndrome complicating calcific uremic arteriolopathy in an ESRD male patient on maintenance hemodialysis following failed kidney transplantation J Parathyr Dis. 2018;6(2):68-71. DOI: 10.15171/jpd.2018.21.

Copyright ( 2018 The Author(s); Published by Nickan Research Institute. This is an open-access article distributed under the terms of the Creative Commons Attribution License, which permits unrestricted use, distribution, and reproduction in any medium, provided the original work is properly cited.
\end{abstract}

\section{Introduction}

Calciphylaxis (or calcific uremic arteriolopathy) has been described as an uncommon but dreaded complication of renal failure characterized by nodular or plaque-like subcutaneous calcification and painful tissue necrosis often leading to ulceration and secondary infection (1-4). Mortality rates range from $30 \%$ in patients with plaquelike lesions and no ulceration to greater than $80 \%$ in patients presenting with or developing ulcerations $(3,5)$. Calciphylaxis, a rare but devastating condition that has continued to challenge the medical community since its early descriptions in the scientific literature many decades ago is predominantly seen in patients with chronic kidney failure treated with dialysis (uremic calciphylaxis) but is also described in patients with earlier stages of chronic kidney disease and with normal kidney function $(6,7)$. High-quality evidence for the evaluation and management of calciphylaxis is lacking at this time due to its rare incidence and poorly understood pathogenesis and the relative paucity of collaborative research efforts (6).

However, an arteriolopathy and calciphylaxis can produce indirect effects as a result of a mass effect of large lesions anywhere in the human anatomy. We present a case of symptomatic superior vena cava syndrome complicating a large intrathoracic calciphylaxis lesion.

\section{Case Presentation}

In February 2016, an obese 48-year-old Caucasian male patient, on hemodialysis since July 2013 following a failed kidney transplant, had complained of unilateral painless right sided facial swelling with occasional right upper extremity swelling, both usually worse on waking up in the morning. Primary renal failure was due to IgA nephropathy. He had received a cadaveric kidney transplant in November 2006 which was lost subsequently to rejection. A right internal jugular vein tunneled hemodialysis catheter that was placed in July 2013 was later discontinued in 2014. An AV fistula was created in June 2013 and had been used since 2014. Additional comorbidities and medical concerns were hypertension, obesity with sleep apnea, mild pulmonary hypertension with right ventricular systolic pressure of $40 \mathrm{~mm} \mathrm{Hg}$ and severe left atrial enlargement (September 2013). Additionally, there were recurrent hyperkalemia, recurrent fluid overload and difficulty to control hyperphosphatemia. Patient also had secondary 


\section{Implication for health policy/practice/research/ medical education}

We presented a case of symptomatic superior vena caval syndrome complicating a large intrathoracic calciphylaxis lesion. The unusual presentation of facial fullness was highlighted and the factors in our ESRD patient that may have predisposed him to symptomatic calciphylaxis and the difficulties of management are discussed.

hyperparathyroidism despite the administration of noncalcium phosphorus binders and high dose cinacalcet as an oral calcimimetic, (Figure 1A-C). Calcium levels were generally within normal range but he had experienced mild hypocalcemia with cinacalcet therapy (Figure 2). Notably, patient non-compliance with dietary and fluid restrictions remained a chronic concern. His outpatient medications were Aranesp $200 \mathrm{mcg}$ weekly, sevelamer $800 \mathrm{mg}$, three tablets $(2400 \mathrm{mg}), 3 \times /$ day with meals, methyldopa $250 \mathrm{mg}$ 2 times a day, venlafaxine, pregabalin and pramipexole for restless legs and peripheral neuropathy, pantoprazole, metoprolol tartrate $25 \mathrm{mg}$ pill 2 times a day, hydrocodone, as needed for pain, hydralazine, cinacalcet $90 \mathrm{mg}$ daily
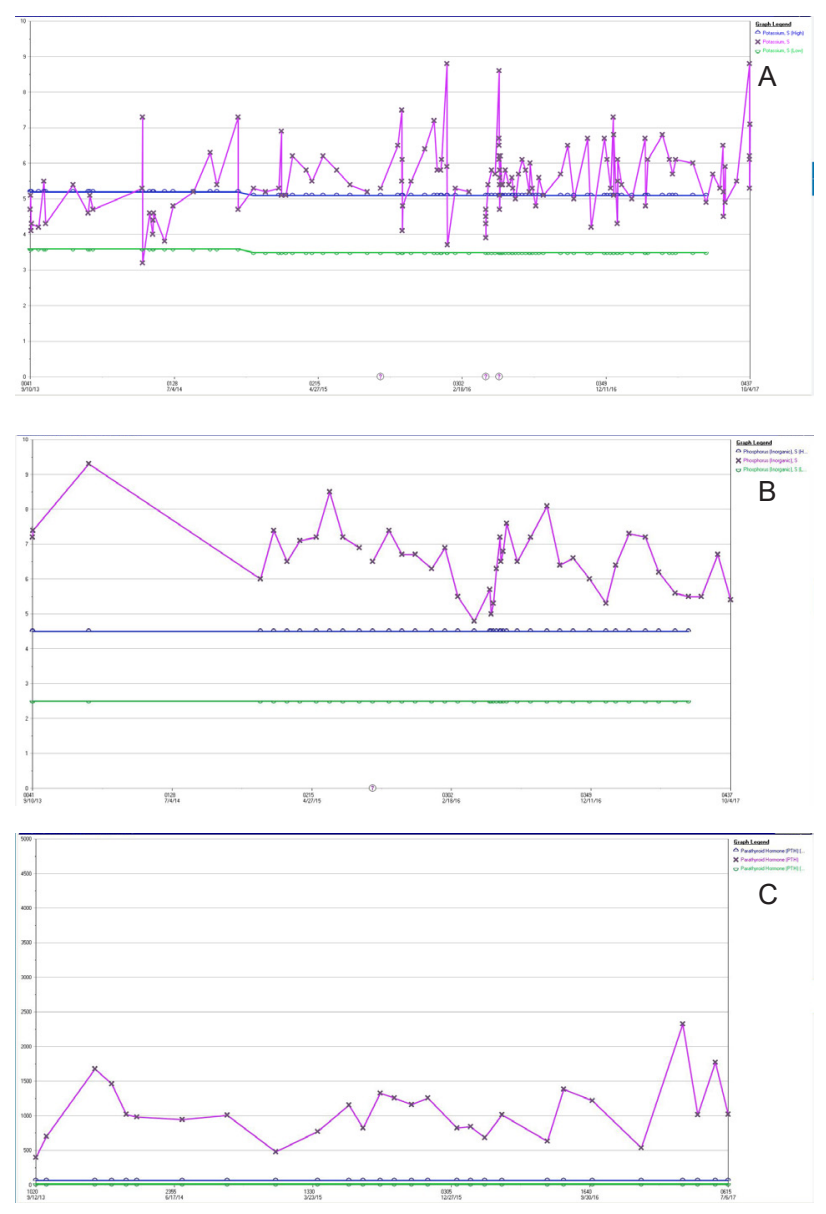

Figure 1. (A) Levels of serum potassium, 2013-2017, demonstrating persistent recurrent hyperkalemia. (B) Levels of serum phosphorus, 2013-2017, demonstrating uncontrolled hyperphosphatemia. (C) Levels of serum PTH, 2013-2017, demonstrating uncontrolled hyperparathyroidism and low-dose azathioprine immunosuppression for the failed kidney transplant. Sometime in 2016, he was started on oral patiromer, $8.4 \mathrm{~g}$ daily, a new potassium-binding polymer, for recurrent hyperkalemia but he has not been compliant with the administration of this agent.

In February 2016, Doppler examinations of the neck veins were negative for any thrombosis including bilateral internal jugular veins, right subclavian vein, and right axillary vein. The left subclavian veins were however not well visualized. A non-occlusive thrombus was identified at fistulogram in the mid right basilic vein. In March 2016, a contrast-enhanced chest CT showed a lobulated area of increased attenuation within the superior vena cava (SVC) just below the thoracic inlet measuring $1.3 \mathrm{~cm}$ in diameter, which appears calcified and produced some narrowing of the SVC. There was a large calcified mass within the right axilla measuring up to $13.7 \mathrm{~cm}$ in greatest diameter, which extended superiorly deep to the scapula and inferiorly along the right lateral body wall $1.3 \times 5.9 \mathrm{~cm}$ (transverse, cephalon-caudad dimension) (Figure 3). Furthermore, smaller dystrophic calcifications were also evident in the medial infra-clavicular space on the left.

Simultaneously, in March 2016, he had complained of a painful right hip swelling that was evaluated by orthopedic surgery. Magnetic resonance imaging (MRI) of the right hip in February 2016 had revealed a large lobulated soft

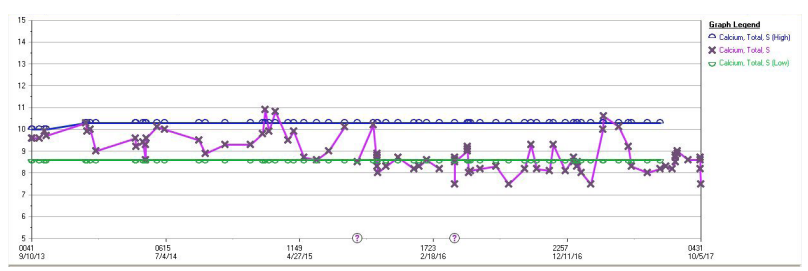

Figure 2. Levels of serum total calcium, 2013-2017.

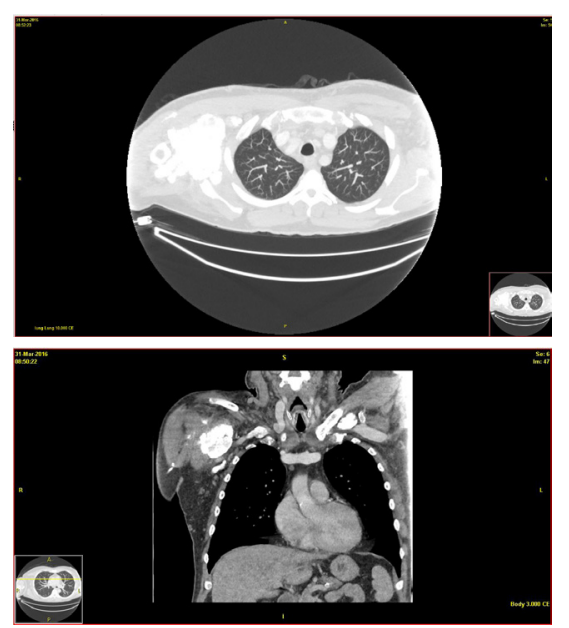

Figure 3. (A) Contrast-enhanced chest CT demonstrating the large calcific lesion extending from the right axilla up into just below the thoracic outlet in transverse plane section. (B) Contrast-enhanced chest CT demonstrating the large calcific lesion extending from the right axilla up into just below the thoracic outlet in coronal plane section. 
tissue mass with heterogeneous mixed hypo-intense and hyper-intense T2-weighted signals with multiple circumscribed lobulations measuring $11.8 \times 6.8 \times 11.3$ $\mathrm{cm}$ and demonstrating extensive corresponding plain film calcifications (Figure 4). There was also edema in the muscle fibers of the gluteal musculature surrounding this lesion. This right hip lesion was resected in the first week of April 2016. The pathology report of the resected right hip lesion showed fibrovascular and mature adipose tissue with chalky calcifications and histiocytes compatible with tumoral calcinosis.

Two weeks later, he underwent superior vena cava venogram with balloon angioplasty carried out by interventional radiology. The venogram demonstrated $80 \%$ stenosis in the mid-SVC secondary to a heavily calcified extrinsic mass seen on previous CT. The stenosis was first dilated to $10 \mathrm{~mm}$, then to $12 \mathrm{~mm}$ at up to 10 atmospheres of balloon pressure (Figure 5A-B). Prolonged repeated balloon inflations up to one minute were performed. There was a consideration to stent the SVC stenosis but an appropriately sized $18 \mathrm{~mm}$ Gianturco stent was not immediately available and the plan was to stent the lesion in the future if symptoms recurred. The unilateral facial swelling has since resolved and the patient is presently on intravenous sodium thiosulfate $25 \mathrm{~g}, 3 \times /$ week at the end of dialysis treatments, since June 2017. It is planned to administer the thrice weekly intravenous sodium thiosulfate for 6 months followed by a review.

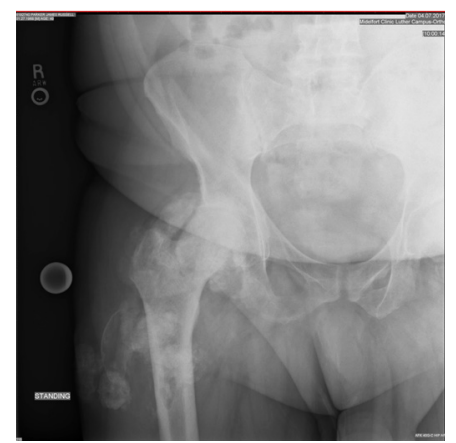

Figure 4. Plain radiograph of the right hip demonstrating extraosseous soft tissue calcified masses.

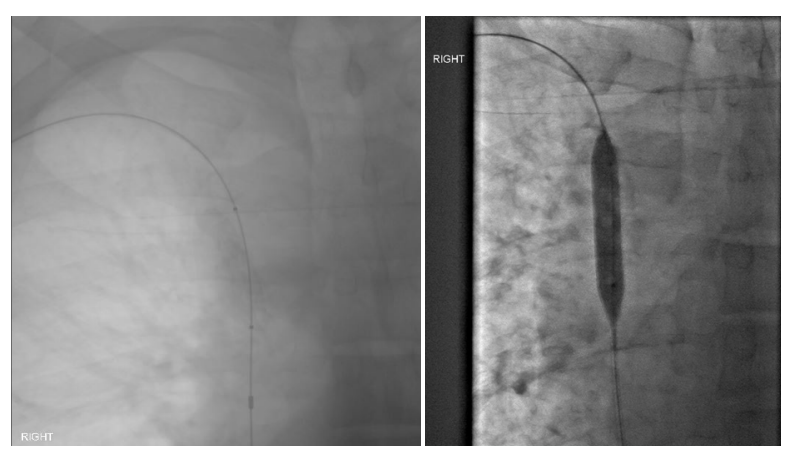

Figure 5. (A) Superior vena caval venogram in April 2016. (B) Superior vena caval venogram followed by balloon angioplasty in April 2016.

\section{Discussion}

Although the cause of calciphylaxis is poorly understood, putative risk factors include female gender, hyperphosphatemia, hypercalcemia, hyperparathyroidism, high calcium $(\mathrm{Ca}) \times$ phosphorous $(\mathrm{P})$ product, use of $\mathrm{Ca}$-containing phosphate binders and vitamin $\mathrm{D}$, and hypercoagulable state $(4,8-10)$. In a recent multivariable conditional logistic regression analysis, diabetes mellitus, higher body mass index (BMI), higher levels of serum calcium, phosphorous, and parathyroid hormone $(\mathrm{PTH})$, and nutritional vitamin $\mathrm{D}$, cinacalcet, and also warfarin treatments were associated with increased odds of subsequent calciphylaxis development (11).

Clearly our patient had very elevated levels of phosphorus, $\mathrm{PTH}$ and $\mathrm{Ca} \times \mathrm{P}$ product. He was morbidly obese with a BMI of $37 \mathrm{~kg} / \mathrm{m}^{2}$ and was receiving cinacalcet. However, he was on sevelamer, a non-calcium phosphorus binder. To our knowledge, this is the first case of SVC syndrome secondary to a thoracic outlet-compressing calciphylaxis mass lesion ever described. His response to one session of robust SVC venogram with balloon angioplasty has been very rewarding. If symptoms recur, the plan is for a placement of an SVC stent by interventional radiology. Notably, Garber et al just recently described a patient who presented with melena and dysphagia due to extraosseous calcification involving the esophagus in a 76-year-old woman with pertinent past medical history of diabetes mellitus type 2 complicated by end-stage renal disease (ESRD) on intermittent hemodialysis for 6 years with secondary hyperparathyroidism (12).

Intravenous sodium thiosulfate has rapidly emerged from a seldom used therapy for the treatment of calciphylaxis to a treatment that is being increasingly utilized globally due to multiple positive outcomes shared in the form of case reports and reviews during the past six years (13). He has so far received about three months of thrice weekly IV sodium thiosulfate, $25 \mathrm{~g}$ infusion given at the end of each hemodialysis treatment, and after six months of this therapy, this would be reviewed by CT imaging of specifically the right thoracic outlet mass that had produced the SVC syndrome.

There already has been several discussions between the patient and general surgery about a potential need for parathyroidectomy in the past. According to consensus guidelines, surgical parathyroidectomy is indicated in patients with refractory hyperparathyroidism (6).

\section{Conclusion}

We described an unusual case of symptomatic superior vena caval syndrome complicating a large intrathoracic calciphylaxis lesion. The peculiar presentation of facial fullness was highlighted and the factors in our ESRD patient that may have predisposed him to symptomatic calciphylaxis as well as the difficulties of management of this rare but often debilitating disease are discussed.

Authors' contribution

MACO, AK, VN and ZJ reviewed the case. AK helped with 
the production of the figures. MACO and ZJ reviewed the literature. MACO completed the draft as well as writing. NA assisted with the draft and editing.

\section{Conflicts of interest}

The authors declared no competing interests.

\section{Ethical consideration}

Ethical issues (including plagiarism, data fabrication, double publication) have been completely observed by the authors. A written informed consent was obtained form the patient for publication.

\section{Funding/Support}

None.

\section{References}

1. Coates T, Kirkland GS, Dymock RB, Murphy BF, Brealey JK, Mathew TH, Disney AP. Cutaneous necrosis from calcific uremic arteriolopathy. Am J Kidney Dis. 1998;32:384-91.

2. Janigan DT, Hirsch DJ, Klassen GA, Mac Donald AS: Calcified subcutaneous arterioles with infarcts of the subcutis and skin ("calciphylaxis") in chronic renal failure. Am J Kidney Dis. 2000;35:588-97.

3. Wilmer WA, Magro CM. Calciphylaxis: Emerging concepts in prevention, diagnosis, and treatment. Semin Dial. 2002;15:172-86.

4. Cicone J, Petronis J, Embert C, Spector D. Successful treatment of calciphylaxis with intravenous sodium thiosulfate. Am J Kidney Dis. 2004;43:1104-8.
5. Fine A, Zacharias J. Calciphylaxis is usually nonulcerating: Risk factors, outcome and therapy. Kidney Int. 2002;61:2210-7.

6. Nigwekar SU, Kroshinsky D, Nazarian RM, Goverman J, Malhotra R, et al. Calciphylaxis: risk factors, diagnosis, and treatment. Am J Kidney Dis. 2015;66:133-46. doi: 10.1053/j. ajkd.2015.01.034.

7. Shen G, Huang R, Liu B, Kuang A. Sodium Thiosulfate in the treatment of lung and breast calciphylaxis: CT and bone scintigraphy findings. Clin Nucl Med. 2017 Sep 1. doi: 10.1097/RLU.0000000000001837.

8. Mazhar AR, Johnson RJ, Gillen D, Stivelman JC, Ryan MJ, Davis CL, et al. Risk factors and mortality associated with calciphylaxis in end-stage renal disease. Kidney Int. 2001;60:324-32.

9. Budisavljevic MN, Cheek D, Ploth DW.Calciphylaxis in chronic renal failure. J Am Soc Nephrol. 1996;7:978-82.

10. Llach F. The evolving clinical features of calciphylaxis. Kidney Int. 2003; 63:S122-4.

11. Nigwekar SU, Zhao S, Wenger J, Hymes JL, Maddux FW, Thadhani RI, et al. A nationally representative study of calcific uremic arteriolopathy risk factors. J Am Soc Nephrol. 2016;27(11):3421-9. doi: 10.1681/ASN.2015091065.

12. Garber A, Arora Z, Welch N, Lapinski J, Burke CA. Extraosseous calcification of the esophagus: clinicopathologic correlates of esophageal mucosal calcinosis. ACG Case Rep J. 2017;4:e108. doi: 10.14309/ crj.2017.108.

13. Hayden MR, Goldsmith DJ. Sodium thiosulfate: new hope for the treatment of calciphylaxis. Semin Dial. 2010;23:25862. doi: 10.1111/j.1525-139X.2010.00738.x. 